\title{
ENTREVISTA A PAUL GILROY: DEL ATLÁNTICO NEGRO A LA MELANCOLÍA POSTCOLONIAL ${ }^{1}$
}

\author{
POR \\ JiM COHEN y JADE LINDGAARD \\ Revue Mouvements
}

Paul Gilroy, quien comienza a volverse conocido en Francia, es una celebridad en el mundo universitario angloamericano y una de las grandes figuras de los estudios culturales británicos. Como autor de Black Atlantic (1993), de Against Race o Between Camps (2000), y de Postcolonial Melancholia (2004), Gilroy ha estado presente en los principales debates de los últimos años sobre la cultura, el racismo, el antirracismo y la condición poscolonial. En la actualidad es profesor del London School of Economics después de haber enseñado varios años en la Universidad de Yale. En la primavera de 2007 visitó París y tuvo su primer encuentro con sus lectores en Francia. Durante su breve estadía Gilroy concedió esta entrevista a la revista Mouvements.

Mouvements: ¿Cuál ha sido su recorrido personal? ¿Qué es lo que lo ha llevado a interesarse por las culturas populares, por la música, la noción de "raza", las culturas negras, la hibridación y lo inglés / lo "englishness"?

PAUL Gilroy: Tengo 51 años. En 1956, cuando nací, mis padres no estaban casados. Mi padre era comunista y abandonó el partido ese mismo año. Mi madre era una mujer alborotadora, aunque no de tiempo completo. Vino de Guyana; era profesora, y no pudo encontrar trabajo cuando llegó a Inglaterra. La gente la veía como una extranjera. Tuvo que trabajar como empleada doméstica por algunos años antes de poder volver a la enseñanza. Crecí en una casa llena de libros. El vecino -mi mejor amigo de la infanciaera un niño de madre francesa y padre argelino. Estas historias son típicas de Londres, y dibujan los contornos de una parte importante de mi mundo.

Fui a la universidad porque eso es lo que la gente hacía. En ese momento llevaba una vida paralela de músico - yo toco la guitarra- y no estaba seguro de querer estudiar. Estaba a punto de abandonar la universidad -me encontraba estudiando literaturacuando mi director de investigaciones me pidió que leyera dos libros: Le damnés de la

1 Publicación original: "De l'Atlantique noir à la mélancolie postcoloniale", Mouvements 3/51 (2007): 90101. 
terre (1961), de Frantz Fanon, y Les Jacobins noir (1938), de C.L.R. James. "Cuando los termines quizás te entusiasmes con Raymond Williams", dijo. Eso fue lo que me hizo quedarme en la universidad y me puso a trabajar. Sin embargo, era mi actividad política lo que entonces contaba. Las personas como yo, de mi generación, no se hubieran imaginado nunca convertidas en profesores. Esa puerta no estaba abierta para nosotros; ir a la universidad era nuestra forma de hacer política.

Más tarde fui a trabajar con el profesor jamaiquino Stuart Hall a la Universidad de Birmingham. Me uní a él porque el Centro de Estudios Culturales que dirigía era un lugar aparte, donde se desdibujaban las fronteras entre las disciplinas y se valoraba el trabajo colectivo. Por ejemplo, éramos los estudiantes quienes conducíamos los exámenes orales de admisión... claro, de forma completamente ilegal. Esto nos motivó a distanciarnos del carácter individualista de los estudios: para poder pasar los exámenes, además de sus investigaciones personales, uno emprendía proyectos comunes con otros estudiantes. Fue así como en 1982 tuve la oportunidad de trabajar en una publicación colectiva, The Empire Strikes Back (1982). La influencia de Stuart era muy grande porque por esos días, con otro grupo de trabajo, había participado en una compilación colectiva publicada por el Centro: Policing the crisis, ${ }^{2}$ que estudiaba las transformaciones del Estado británico en los 70, antes de Margaret Tatcher, y la formación del racismo populista. Para esto se apoyaron en sus experiencias como militantes asociativos a nivel local.

Cuando la primera ola de inmigrantes llegó a Gran Bretaña, después de la Segunda Guerra, fueron considerados como una de las poblaciones más tranquilas. Estaban lejos de ser vistos como criminales; muy al contrario, eran apreciados como gente respetable y respetuosa de la ley, muy dentro de los comportamientos "victorianos". Pero poco a poco, a medida que se modificaba la composición demográfica de la sociedad, el Estado (la policía, la ley, los tribunales, la justicia penal, el sistema carcelario) comenzaron a identificar a los hijos de los inmigrantes como factores de desorden social.

La tesis del libro de Stuart Hall es que las representaciones racistas movilizadas por el sentido común popular dieron lugar a la articulación del populismo autoritario. La noción de "populismo autoritario" desarrollada por Stuart Hall se desprende, creo yo, de su lectura de Nicos Poulantzas -autor de L'État, le pouvoir, le socialisme (1978), y a quien entonces nos gustaba discutir- y de su compromiso comunista asociativo, que me parecía muy derechista (risas). Esta es una reflexión alrededor de la manera en que la noción de raza es utilizada para articular una respuesta más general a un cierto tipo de crisis política y económica, una crisis "gramsciana", permanente, donde el racismo aporta puntos de seguridad en el análisis. Es decir, se trataba de ver el racismo como un problema central, en sí mismo constitutivo de relaciones sociales específicas.

Parte de este texto, complementado con otros artículos de la década de los noventa, fue publicado en francés: Le populisme autoritaire, puissance de la droite et impuissance de la gauche au temps du thatchérisme et du blairisme. Véase Hall. 
Entonces no habíamos leído Orientalismo de Edward Said y no frecuentábamos a Foucault. Nos inventamos nuestra propia lectura de las cosas. La primera vez que presenté los avances de mi investigación a mi director era muy tímido y no tenía confianza en mí mismo: “¿Cómo define usted el racismo?”, le pregunté. Era muy difícil hacerle esta pregunta porque durante los primeros tres años de mis estudios superiores yo a duras penas había hablado. Él me respondió: "yo no me arriesgaría nunca a semejante cosa tan difícil". Fue así como resolvimos escribir nuestro libro con el propósito de avanzar en nuestra reflexión. Trabajamos a partir de C.L.R. James, y, por supuesto, de Frantz Fanon, y de ciertas referencias de la historiografía del Atlántico que se quedaron conmigo desde entonces - como Roger Bastide y Edward Braithwaite, quienes trabajaron sobre el proceso de criollización de Jamaica e incluso Brasil-. En ese entonces Stuart Hall trabajaba para la Unesco en París y había creado vínculos con sociólogos y antropólogos latinoamericanos como el mexicano Roger Bartra. Ellos también influenciaron mis trabajos.

Stuart Hall escribió un texto para la Unesco sobre las diásporas que se titulaba, creo, "La diaspora africaine est en vie et se porte bien dans le Caraïbes". Fue la primera vez que oí hablar de la "diáspora africana" dentro de un discurso científico. Yo conocía esta noción por la música o por la cultura popular rastafari, pero nadie hasta el momento la había constituido como una noción sociológica. Fue Stuart quien, gracias a las conversaciones que entabló con otros investigadores, me hizo tomar conciencia de esta cuestión.

M: En Francia muchos lo han descubierto gracias al único libro suyo hoy traducido al francés, diez años después de su aparición en 1993: Black Atlantic. En este trabajo usted opone a una visión esencialista de la cultura negra, frecuente en los estudios culturales, la idea de un "Atlántico negro" entendido como un espacio público transnacional cuyos contornos están unidos a los de la diáspora africana, y donde se generan y se mezclan las culturas negras desde los tiempos del sistema esclavista. El libro también es una fuerte crítica a las lecturas dominantes de la modernidad occidental. ¿Qué queda en nuestros días de ese "Atlántico negro" como espacio político?

PG: Cuando escribí ese libro la tecnología no era la misma de hoy. No había correo electrónico, por ejemplo. Tampoco llegué a utilizar la palabra "globalización". No había leído The Nomos of the Earth de Carl Schmitt, ni The Invention of the Americas de Enrique Dussel. Todo lo que sabía era que quería escribir un libro del corte de Orientalismo, esto es, algo que me permitiera proponer un tipo de enfoque que fuera aplicable en otras disciplinas.

En nuestros idiomas - esto es particularmente cierto en el francés y el inglés- el concepto de cultura está muy ligado a la tierra, a la agricultura, al suelo. No consideramos el océano, los barcos o el comercio como lugares de cultura. Para nosotros la cultura comienza con la tierra firme; todo lo demás no es visto sino bajo la forma de intersticios.

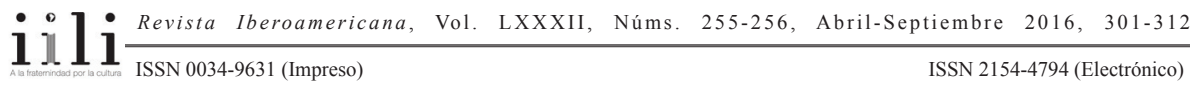


Yo no estoy de acuerdo con esto. Mi ciudad, Londres, ha sido históricamente la "vena yugular" del imperio: a finales del siglo XVIII los intereses británicos en el Caribe propiciaron la emergencia de una cierta ciencia policial. El Panopticón ${ }^{3}$ de Jeremy Bentham fue diseñado por su hermano Samuel, quien trabajó en los puertos reales en la estandarización de la producción de los barcos del Imperio. Existen, entonces, ciertos vínculos entre esta ciudad, este Estado y este mundo colonial - esta modernidad- que marcan un proceso de construcción de Estado que no se limita únicamente a un pequeño entorno europeo, sino que toma una forma transnacional que está fundamentalmente asociada al mar, a través del esclavismo.

En pleno siglo XVIII, Oludah Equiano ${ }^{4}$ llega a las costas de Inglaterra en barco: sabe que si desembarca y pone pie en tierra firme puede pedir asilo gracias al juicio de Lord Mansfield que protege a los esclavos que permanecen en Inglaterra y prohíbe su reintegro a la esclavitud. Pero Equiano queda acorralado en el barco. Se tomará ocho años para poder salir: deberá regresar a América, trabajar en las islas del Caribe y los cayos de la Florida para ahorrar el dinero que le permitirá comprar su libertad. La historia nos obliga a pensar en lo que Peter Linebaugh denomina la "hidrarquía", esto es, el sistema de poder del agua, y es una buena introducción para entender y analizar una serie de problemas imbricados, como la producción del poder imperial a través de las ciencias policiales y del orden, de los salarios o la flota real. Con esta idea yo definí mis compromisos políticos. En mi secta de ultra-izquierda habíamos trabajado en la historia del salario; sabíamos que el salario había sido inventado en los puertos y comprendíamos que procedía de una cultura portuaria que participaba en la producción de formas de poder.

M: ¿Existe un "Atlántico negro" en nuestros días?

PG: No, no creo. Espiritualmente hablando, para mí el "Atlántico negro" acaba con la muerte de Bob Marley en 1981. Se trata del fin de una voz de corte etiopista y del comienzo de un movimiento hacia el Islam. Yo pensaba que este proceso tomaría una dirección más afrocentrada, pero no fue el caso. La tecnología juega un papel importante en el fin de lo que entiendo por "Atlántico negro": la música ya no es tan central. Ella está todavía ahí, no quiero decir que haya desaparecido, pero no juega el mismo rol que antes. Los sonidos digitales y los videos producidos por las culturas negras evocan otras cosas en la imaginación. Puede ser, podríamos decir, que la noción de "Atlántico negro" funcione más en una geografía política dominada por un eje este-oeste que por uno norte-sur. Luego la gente se fue apropiando del concepto de "diáspora", del que

3 El panopticón es una forma de prisión inventada por el filósofo inglés Jeremy Bentham (1748-1832) que permite a una persona observar a los prisioneros sin que ellos lo sepan.

4 Olaudah Equiano o Gustavus Vassa (1745-1797), nacido en África (en la futura Nigeria), luchó por la abolición del esclavismo en Gran Bretaña. 
antes no se hablaba mucho, pero que constituye hoy una referencia muy difundida. Incluso se utiliza la palabra "diáspora" en lugar de "inmigración".

El desafío a partir de ahora debería ser dibujar un mapa del "Atlántico negro" que comprenda la bahía de Guantánamo. En Cuba, durante la guerra con España y Estados Unidos entre 1895 y 1898, apareció por primera vez el campo de concentración, entendido como un producto de la tecnología política. Esto ocurrió mucho antes del Guantánamo que actualmente conocemos. Creo que debe haber un modo de pensar la forma colonial de gobierno en relación al proyecto de "Atlántico negro", tal como yo lo concibo. Sería necesario que la bahía de Guantánamo y Condoleezza Rice figuraran en nuestro nuevo mapa del "Atlántico negro", pero no sabemos si es posible dibujar este mapa. Los afroamericanos, así como los europeos negros, deben decidir antes si quieren o no ser parte del mundo. Yo he vivido en América: yo creo que los afroamericanos ante todo quieren ser americanos.

M: Pero no todos los afroamericanos quieren ser Condoleezza Rice...

PG: Seguro que no, pero tampoco aspiran necesariamente a generar relaciones con África. Una de las últimas cosas que hice en Estados Unidos antes de regresar a Inglaterra fue pasar un buen tiempo en el gran Sur, en Alabama y Mississippi. Varios de los amigos con quienes hice música aún viven allá. Puede parecer sorprendente: algunos de los viejos militantes del Freedom Movement de los años 60 actualmente se reconocen en Condoleezza Rice. Incluso, si no se definen como republicanos, se sienten representados por ella. Ella no es como Barack Obama, cuyo padre es keniano y su madre blanca: ¡Ella viene de Bama! Como sabrás, en ese estado, Alabama, ya no hay más algodón, pero sí una fábrica de Mercedes 4x4; desde Birmingham a Tuscaloosa hay, además, todo un discurso anti inmigración que se expresa en el rechazo de negros y blancos hacia los latinos. Por razones como esta no estoy tan de acuerdo con que se diga que el "Atlántico negro" perdura en nuestros días.

M: Hoy Francia experimenta una suerte de "metamorfosis poscolonial": aquí se gasta mucha energía tratando de determinar las posibles continuidades entre el pasado colonial y el presente supuestamente poscolonial. ¿Cómo analiza usted el problema de la continuidad entre el colonialismo y la actualidad?

PG: Me he mantenido siempre reticente a analizar lo que pasa en nuestras ciudades como una extensión del colonialismo, o como una especie de "endocolonialismo". Los autores afroamericanos han utilizado mucho la noción de "colonia interior" en su tentativa de adaptar a su mundo una lectura que viene de los líderes independentistas. Hacen una analogía con la situación colonial.

En nuestros movimientos de protesta la gente era atacada y molida a palos por la policía. Uno podía decir que había algo en la ley que hacía posible que las personas se comportaran de esta manera, algo formalmente asociado al pasado y la tradición coloniales. Las personas que cometían esas brutalidades de alguna u otra forma habían 
conocido el Imperio. Pero hoy ya no estamos hablando de las mismas personas; si hoy miro por la ventana puedo ver a un policía negro cometiendo brutalidades. No ignoro que exista un precedente colonial en esto. Lo que quiero señalar es que en nuestros movimientos una de las líneas políticas era no entrar a formar parte de la policía. Durante aquellos años ninguno de nosotros quería convertirse en policía-luego había muy pocos policías negros-, incluso cuando C.L.R. James nos decía que el problema del racismo estaría resuelto si muchos de nosotros nos vinculábamos a los cuerpos policiales, pues así dejaríamos de correr riesgos. Si tú vas hoy a Inglaterra con tu pasaporte y terminas abusado, asaltado o herido por un agente de la policía, hay buenas posibilidades de que la persona que te hace sufrir eso sea poscolonial. Esos comportamientos no son reducibles a la lógica del mundo colonial, que es la de un mundo completamente dividido en dos, mecanizado.

M: Entonces el "pos" de "poscolonial" sí es significativo para usted...

PG: Desde luego. Como ejemplo, quisiera anotar que en el barrio donde vivo, en Londres, hay muchos jóvenes negros franceses que huyeron de Francia. No sabemos muy bien de qué querían escapar. El multiculturalismo de Europa, que existe y defiendo, se hace mediante la práctica, pero depende también de muchas variables que se salen de nuestras manos. El poder está ahí para nada...

M: Su libro Postcolonial Melancholia (2004) no ha sido traducido al francés. ¿Podría explicarnos de qué se trata esta idea de "melancolía poscolonial"?

PG: Sí, podríamos poner un ejemplo a pequeña escala. Si yo salgo de mi casa y quiero comprar llantas, voy donde "los" egipcios. Si quiero repuestos eléctricos para mi carro voy donde "los" chipriotas o "los" turcos. Si yo quiero conseguir papeles falsos para demostrarle a la policía que mi carro está en condiciones de andar, voy... voy a otro lado (risas). Hay numerosas pequeñas economías que componen un escenario multicultural, pero esto no es muy significativo. Es decir, uno no oye a nadie decir: "Miren lo maravilloso que es que todos podamos comunicarnos". Mientras el dinero cambie de manos los problemas prácticos están resueltos: mi carro funciona bien, hay alguien que cuida a mi bebé, alguien que va a recoger a mi hijo a la escuela...

M: Para que eso sea así no es necesario un aparato legislativo específicamente multiculturalista...

PG: En absoluto. Regularmente voy al hospital a hacerme pruebas de sangre: allá puedo encontrarme con cerca de cuarenta personas hablando en veinticinco idiomas distintos. Podríamos buscar los ingredientes de un multiculturalismo durable en diversos espacios institucionales, económicos, antropológicos. Ahora, para llegar a él, para que sea perdurable y vivible, debemos asumir nuestro pasado colonial, y esto en Inglaterra y otros países europeos no ocurre de ninguna forma. La salud del multiculturalismo está ligada a la capacidad de reflexionar sobre la memoria y las heridas no sanadas del pasado colonial. Se trata de darse al trabajo de la memoria, en el sentido freudiano del

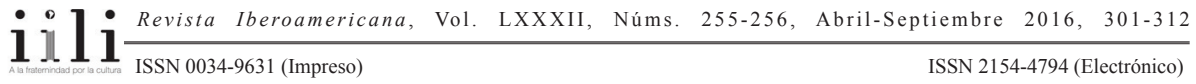


término. He sido muy influenciado por los psico-sociólogos que partieron de Freud para analizar el proceso de "desnazificación" de Alemania, en particular por los Mitscherlich, la pareja que publicó The Inability to Mourn (1975). Sé que la idea de "duelo" está de moda - en Estados Unidos podrías obtener un diploma en "estudios del duelo", que es la etapa posterior al trauma: los norteamericanos están todos de duelo ahora...

Pero hablando seriamente, los Mitserlich me interesan porque según ellos los alemanes no pueden asumir su pasado y permanecen prisioneros en él, pues se piensan como las principales víctimas del sistema nazi. Esto me recuerda también a los británicos: ellos se piensan como las víctimas de su propia historia imperial. En Inglaterra tenemos algunos historiadores revisionistas que no dejan de publicar libros, como Niall Ferguson, o Linda Colley, quien supuestamente escribe contra la guerra y el imperialismo estadounidense, pero en uno de cuyos libros, Captives, no hace sino hablar de ingleses que fueron hechos prisioneros por los indígenas. Es una de las escritoras favoritas del gobierno, una especialista que se ha convertido en una autoridad en "el significado de la britishness".

Los historiadores revisionistas del Imperio piensan que pueden escribir sus libros porque actualmente es posible el regreso del Imperio. Parte de lo que pasa en Mesopotamia, en Afganistán, en Pakistán y en ciertos lugares de África sin duda tiene que ver con lo que dicen ciertas personas: "las cosas iban mejor allá cuando teníamos las colonias". Un diplomático intelectualoide, Robert Cooper - quien trabaja actualmente con Javier Solana- fue quien le llenó la cabeza a Tony Blair con todas esas estupideces.

Las condiciones de ese retorno del Imperio también hacen parte de la "melancolía poscolonial", pues tampoco en este caso asumes el pasado. Pero las gentes de Afganistán, Irán, Pakistán o de Mesopotamia sí se acuerdan de lo que les pasó, y no precisamente porque lean artículos de Marx en sus periódicos. Hay un déficit, un cierto desfase: estamos viviendo una guerra de información, y sin embargo quienes pelean a nuestro lado no tienen ninguna información sobre el pasado. Todo está ligado: la multiculturalidad posible y el trabajo de la memoria del Imperio.

Un debate que se está dando actualmente en Francia, sobre el modo en que se cuenta la historia en los libros escolares, se ha desencadenado también en Inglaterra y Japón. Se trata de una historia cosmopolita: ¿cómo contarla entonces? Para probar que no se trata de un problema de melancolía, sería necesario resolver de manera más sana lo que se hizo hasta el presente.

M: Si estamos ante un problema cosmopolita, ¿cree usted que hay una solución cosmopolita?

PG: Nunca discutimos este punto de esta manera. Es en el corazón de la gestión de la identidad nacional -en un nuevo entorno político saturado de información pero en el que crecen las tasas de analfabetismo- donde vemos el sistema educativo hecho jirones. No quiero mostrarme muy exagerado al respecto, porque corro el riesgo de 
irme muy a la derecha, al lado de las personas que defienden la idea de que uno va a la universidad para "adquirir educación". Por mi parte no hablo de la universidad, sino de todo el sistema educativo. Esta guerra de la información que nos plantea cuestiones tan cruciales, está igualmente ligada a la cultura de la ignorancia que se encuentra promovida por el modo de funcionamiento de cierto sistema político. Gordon Brown, nuestro nuevo dirigente, dice que ha encontrado muchos africanos para quienes "ya es hora de que de que Gran Bretaña deje de excusarse por su pasado imperial". Soy un viejo crítico literario, y por eso me interesa entender por qué él desplaza la responsabilidad de esta idea a sus interlocutores africanos. No se contenta con decir, simplemente, "ya es hora de que Gran Bretaña deje de excusarse de su pasado colonial". Dice: "muchos africanos dicen que...". Para mí, este desplazamiento es un sinónimo del problema. Jamás he entendido a los británicos que se excusan de su pasado colonial, jla idea misma de que los ingleses hayan pasado tanto tiempo pidiendo perdón me parece muy graciosa! Sobre este punto no puede haber nunca ninguna excusa: nuestro mundo sería muy distinto si esas excusas hubieran sido verdaderamente pronunciadas, si hubiera habido un reconocimiento, un trabajo de la memoria.

M: Para varios críticos, como el sociólogo Stanley Aronowitz, lo que usted trata de hacer en su libro Against Race resulta utópico porque las fuerzas sociales necesarias para acabar de una vez por todas, a gran escala, con la idea de raza, no existen en la realidad.

PG: ¡No existirán en la realidad en la que vive Stanley! Él escribió una crítica afectuosa y generosa de mi libro, pero el problema es que él habita en un nomos racial que se llama Manhattan, iy es seguro que las fuerzas sociales de las que habla no existen allá, pero sí existen a mi alrededor y hacen parte de mi vida cotidiana!

M: ¿No cree que Nueva York sea multicultural?

PG: Sí, pero esa ciudad vive su diversidad según las reglas norteamericanas. Esas reglas no son generalizables, en particular aquella que tiene que ver con su éxito en términos de colonialismo triunfante -sin duda su único éxito-.

En cuanto a la utopía... Voy a contarte una historia: después de la elección del gobierno de Blair se llevó a cabo una investigación para decidir sobre el tipo de política que su gobierno tendría en cuestiones raciales. Habían prometido organizar un debate para establecer las nuevas leyes, pues consideraban que los laboristas no tenían razón y que con ellos las cosas serían diferentes. Por esos días me invitaron a la casa de una rica residente de Notting Hill Gate que estaba participando en ese asunto. Me sirvieron té y nos sentamos para hablar de lo que iba a pasar. Yo le había hablado durante media hora cuando dijo: "Usted no es razonable. Lo que propone me recuerda lo que uno dice de la escritura aún mal formada de los niños: no está terminado, no está aún formado”. ¡Me siento orgulloso de no "estar terminado"! Ernst Bloch me marcó mucho, en particular su idea de la utopía del "no todavía".

Esto lo aprendí cuando viví en el Atlántico, y también está asociado a la música. Existe una relación entre la utopía y la música: hay cosas que uno puede escuchar sin

$111 \frac{\text { Revista Iberoamericana, Vol. LXXXII, Núms. 255-256, Abril-Septiembre 2016, 301-312 }}{\text { ISSN 2154-4794 (Electrónico) }}$ 
poderlas ver ni comprender. Esto fue lo que traté de definir al final de Black Atlantic con la noción de lo "sublime del esclavo". Si se me acusa de ser romántico, me defenderé diciendo: “¿cuál es el problema de una política fundada en el beso?”

M: ¿Cómo podría generalizarse el modelo de "ciudad convival”, tal y como usted lo ve, al resto de la sociedad?

PG: Me temo no ser suficientemente sociólogo. Responderé que esta convivialidad, que para mí es un componente ordinario de la vida urbana poscolonial, no ha sido nunca validada por la investigación económica y que no sé si va a sobrevivir. Supongo que no hay razones para que no se perpetúe, pero tal vez nos convenga mantenernos en guardia. Además, en esta situación de "interacción convival" puede haber racismo. Ocurre frecuentemente. En mi barrio hay una gran cantidad de polacos: viven allá desde los tiempos de su masiva llegada -600 mil personas, la mayor inmigración en la historia británica. Ellos se ven a sí mismos como aquellos que vinieron a Gran Bretaña a pilotar los aviones que combatieron contra los nazis durante la guerra. Ellos se sienten legítimos... ¿por qué razón quisieran sentirse negros? Cuando yo era joven e iba a los bares, sólo tenía la opción de entrar en un bar de blancos o en uno de negros. Los negros venían del caribe y los blancos eran irlandeses. Hoy en día esta distinción ha desaparecido. Todo el mundo está mezclado: tú vas a un bar y encuentras negros y blancos, y todos los blancos son irlandeses u originarios de Europa oriental. El racismo continúa existiendo, pero en el interior mismo de este racismo es posible encontrar los medios para invertirlo, los recursos para contenerlo. Si a ti te gusta la idea de "capital social" - este no es mi caso- podrías decir que hay formas de capital social que hacen parte de esta cultura transversal.

M: Teniendo en cuenta su crítica del esencialismo racial, ¿cómo puede justificar las políticas que toman en cuenta, de forma explícita, categorías raciales para luchar contra la discriminación? ¿Cómo reconcilia la necesidad de ir "más allá" de la raza con la urgencia de combatir contra el racismo?

PG: Nuestros gobiernos saben que el racismo está mal, pero no saben que el antirracismo está bien. Los movimientos antirracistas son tan antiguos como la historia de la izquierda, se remontan a los primeros movimientos obreros. Por ejemplo, en el origen del movimiento abolicionista, vemos que Equiano estaba relacionado con Thomas Hardy, un zapatero que vivía en el centro de la ciudad y que fue la primera persona en crear una organización obrera, la London Corresponding Society. La historia de estas luchas se entreteje, desde la lucha contra el esclavismo, pasando por la historia de la causa feminista, hasta el momento en que el socialismo tuvo en cuenta la protección de los pueblos indígenas en el siglo XIX. Esto no le interesa a la mayoría de la gente, pero estamos hablando de una historia de interconexiones que viene desde hace por lo menos doscientos años. Durante veinticinco años, sobre todo desde que escribí There Ain't No Black in the Union Jack (1987), los movimientos antirracistas se han vuelto

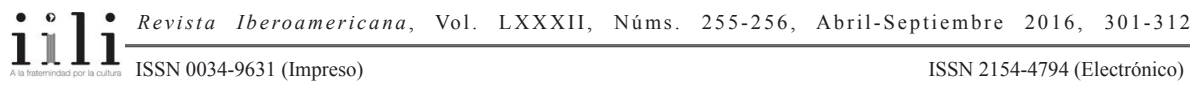


muy visibles. Yo creo que su primer momento de visibilidad fue cuando se formó "Rock against Racism", en 1976. Mientras Eric Clapton, David Bowie y otros tantos hacían comentarios racistas, gracias a "Rock against Racism", ser racista dejó de ser algo “cool". Es una de las ganancias de esta época. Los militantes antirracistas, originalmente exteriores al poder, llevaron esta nueva cultura al interior del aparato del Estado a nivel local -un movimiento interrumpido por la llegada de Tatcher al gobierno-.

El racismo ha sobrevivido. Cuando se produjeron los ataques de julio de 2005 en Londres, el gobierno británico dijo: “estamos viviendo nuevamente los bombardeos, el regreso de la Segunda Guerra Mundial. Otra vez somos esa población que debía refugiarse bajo tierra para escapar a los bombardeos, pero somos fuertes y seguiremos bebiendo nuestro té". Implícitamente, este mensaje quería decir que estábamos regresando a un mundo sin negros, un mundo más simple, sin extraños entre nosotros. Mientras tanto, el alcalde de Londres enviaba un mensaje muy diferente: "Somos una ciudad del mundo, un pueblo cosmopolita. Quienes vivimos aquí venimos de todos los lugares del mundo, ya no somos los mismos que durante la Segunda Guerra. Hemos cambiado". Los dos discursos, las dos formas de entender la situación se enfrentaron: la primera llena de racismo nacionalista, la otra marcada por una cultura cosmopolita, quizás utópica. En todo caso, un antirracismo político se había formado. Más tarde lo critiqué cuando se tornó claramente intervencionista en su orientación, y muy marcado por las tecnologías raciales norteamericanas. El antirracismo puede volver más fuerte la democracia. Está en nuestras manos persuadir a nuestros gobernantes de que el racismo no sea simplemente un "mal que hay que combatir", sino que además el Antirracismo, con "A" mayúscula, puede nutrir un proceso político positivo y generar avances jurídicos importantes. En nuestras manos está llevar el asunto de forma política: no se trata de una cuestión prepolítica, en el sentido de que sea "un sentimiento que compartimos"; tampoco se trata de una situación post-política, de una simple cuestión de comportamientos.

M: ¿Qué piensa de las categorías etno-raciales como recurso para disminuir la discriminación?

PG: Lo que me interesa no es que se elimina la noción de raza, sino que se ponga fin al racismo. No veo de qué manera un posible fin del racismo sea contradictorio con el uso de ciertas categorías. En los Estados Unidos existe esta contradicción, pero no veo por qué tendría que darse la misma situación en otros países. Sabemos que estamos contra el racismo... no obstante, todavía nos hace falta saber en favor de qué estamos. Debemos ser capaces de decir que podemos imaginarnos un mundo sin jerarquías raciales. Si no somos capaces de decirlo, ¿qué ocurrirá? Nos encontraremos en una situación en la que diremos: "tendremos razas, pero eso no será grave porque no habrá conflictos"... ¿Entonces dónde está la utopía? (risas).

Para mí, el apego a la idea de raza se disminuirá si deja de haber gente lastimada a causa del racismo. No se puede ir propiamente contra la noción de raza, pero sí contra

$111 \frac{\text { Revista Iberoamericana, Vol. LXXXII, Núms. 255-256, Abril-Septiembre 2016, } 301-312}{\text { ISSN 2154-4794 (Electrónico) }}$ 
las formas institucionales del racismo que hay en los procedimientos gubernamentales. Desde hace ya bastante tiempo las combatimos, es cierto, pero ahora estamos ante un nuevo problema, la "seguricracia". En la actualidad todo lo relacionado con inmigración se plantea en términos de "seguridad".

Cuando tienen lugar las autodenominadas "estadísticas étnicas", las personas tienen toda la libertad de autodesignarse, de clasificarse a sí mismas. En Inglaterra, cuando este tipo de medida apareció, hubo quienes se declararon "Caballeros Jedi"... Esto plantea ciertos problemas (risas). Lo que en el fondo me intriga es por qué estas medidas levantan tanta oposición en nombre de la ciudadanía. La tradición republicana que promueve este tipo de relación con la ciudadanía necesita renovar su genealogía.

M: Además de sus libros, donde expone su trabajo teórico, publica también artículos sobre las culturas populares, con temas que interesan al público en general: analiza al personaje Ali G, creado por el comediante Sasha Baron Cohen, defiende al rapero The Streets... ¿Puede la cultura popular generar una dinámica política?

PG: Para mí, Ali G es como Las cartas persas de Montesquieu. En pleno siglo XIII, esta lectura de la Ilustración demuestra que para comprender su sociedad es necesario convertirse en un extranjero. Cuando apeló a Persia como dispositivo de interpretación de su propia sociedad, Montesquieu era más libre de lo que somos hoy. ¡Alí G hace lo mismo! Él juega con lo que mi amigo Zygmunt Bauman llama la "proteofobia" de los racistas, pues nadie puede saber en realidad quién es Ali G. ¿Acaso es un negro? ¿Un judío blanco haciéndose pasar por negro? La dimensión "proteiforme" de este extranjero, el xenos que representa -el xenos intrínseco-, tiende un puente que llega hasta el siglo XVIII. La conclusión política que saco en claro es la importancia de poner en duda el deseo de categorizar las cosas, el deseo de saber "quién es quién". Ali G ha suscitado muchas reacciones de cólera porque ha sido interpretado como un judío blanco que roba la cultura de otros. La prueba sería su manera de hablar, inspirada en la nuestra para burlarse. Creo que la cuestión aquí es la siguiente: ¿De qué nos reímos cuando nos reímos de Ali G, de su performance, de su singular condición "proteiforme"? Yo creo que nos estamos riendo de sus intentos desesperados de parecer un negro norteamericano. Eso es lo mejor de su broma. La idea de que el barrio donde vive es un ghetto, cuyas reglas son las de la cultura afroamericana, con pistolas y todo eso, resulta ridícula.

En cuanto a The Streets -aunque no me gusta mucho lo que hizo después de su primer álbum- mi lectura política consiste en observar su abandono de todo registro político, ese momento en que la música se convierte en un lugar donde ya nadie es "político". Una de sus canciones compara la identidad racial y política con las diferentes drogas que la gente toma antes de irse de fiesta: algunos toman anfetaminas y otros cocaína, unos fuman marihuana y los otros toman éxtasis. No hay nada ontológico ahí. En cierto sentido, esta canción defiende la diferencia racial como una mera elección de estilo de vida. Se trata de la supresión de la política, del triunfo de la antipolítica, lo

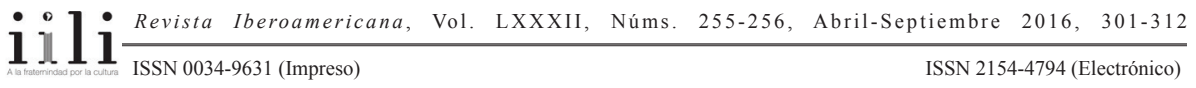


cual tiene, sin duda, un significado político: nos está demostrando que nuestra cultura política está en una burbuja. $\mathrm{Al}$ interior de esa burbuja las cosas parecen muertas, pero afuera pasan muchísimas cosas (risas).

Traducción de Joaquín Uribe

BibLIOGRAFíA

Gilroy, Paul. There Ain't no Black in the Union Jack: The Cultural Politics of Race and Nation. Chicago: The U of Chicago P, 1987.

Hall, Stuart. Le populisme autoritaire, puissance de la droite et impuissance de la gauche au temps du thatchérisme et du blairisme. Paris/Amsterdam: Éditions Amsterdam, 2007.

James, C. L. R. Les Jacobins noirs. Toussaint Louverture et la révolution de SaintDomingue. 1938. París: Éditions Amsterdam, 1984.

Mitscherlich, A.M. The Inability to Mourn, Principles of Collective Behavior. New York: Grove Press, 1975.

Poulantzas, N. L'État, le pouvoir, le socialisme. París: Presses Universitaires de France, 1978.

VV.AA. The Empire Strikes Back-Race and Racism in'70s Britain. Hutchinson: Centre for Contemporary Cultural Studies, 1982. 